\title{
24-epibrassinolide restores nitrogen metabolism of pigeon pea under saline stress
}

\author{
Ronaldo José Durigan Dalio ${ }^{1,2}$, Hildete Prisco Pinheiro ${ }^{3}$, Ladaslav Sodek and Claudia Regina Baptista Haddad ${ }^{\text {* }}$
}

\begin{abstract}
Background: Several studies have shown that brassinosteroids attenuate the effects of salt stress. However, nothing is known about their effects on amino acid transport, nor the effects of these hormones on nitrate uptake under saline conditions. This study set out to determine the effects of 24-epibrassinolide, at concentrations of 10-7 M and $0.5 \times 10-9 \mathrm{M}$, and clotrimazole (inhibitor of brassinosteroid synthesis), at 10-4 M, on nitrate uptake and metabolism in plants of C. cajan (L.) Millsp, cultivar C11, growing under salinity. The following aspects were analyzed: levels of proteins, amino acids, nitrate, nitrate reductase of roots and the composition of xylem sap amino acids.

Results: Salinity reduced the proportion of N-transport amino acids ASN (the major component), GLU, ASP and GLN. The effect of the hormone in reducing the adverse effects of salt was related to the reestablishment (totally or partially) of the proportions of GLU, ASN and GLN, transported in the xylem and to the small but significant increase in uptake of nitrate. Increased nitrate uptake, induced by 24- epibrassinolide, was associated with a higher activity of nitrate reductase together with greater levels of free amino acids and soluble proteins in roots of plants cultivated under saline conditions.

Conclusion: The decline in several components of nitrogen metabolism, induced by salt, was attenuated by 24-epibrassinolide application and accentuated by clotrimazole, indicating the importance of brassinosteroid synthesis for plants growing under salinity.
\end{abstract}

Keywords: Cajanus cajan; Brassinosteroid synthesis inhibitor; Nitrate uptake; Nitrogen metabolism; N-transport amino acids; Saline stress; Xylem amino acids; Xylem exudate

\section{Background}

Brazil has around 90 million hectares of salinized soils (FAO 2008). Salt stress adversely affects the development of plants (Zheng et al. 2008; Türkan and Demiral 2009, Galvan-Ampudia and Testerink 2011). Among the adverse effects of salts are the altered uptake and transport of nitrate (Rubinigg et al. 2003; Parida and Das 2004; Carillo et al. 2005; Maaroufi-Dguimi et al. 2011). Reduced nitrate uptake affects nitrogen assimilation (Silveira et al. 2001; Qu et al. 2011), with consequent alterations in amino acid and protein metabolism (Surabhi et al. 2008; Younis et al. 2009; MaaroufiDguimi et al. 2011). Nevertheless, very few studies (Cramer et al. 2002) have investigated changes in amino acid transport to the shoot via xylem under these

\footnotetext{
* Correspondence: chaddad@unicamp.br

'Department of Plant Biology, Institute of Biology, State University of

Campinas-UNICAMP, CP 6109, Campinas, SP 13083-970, Brazil

Full list of author information is available at the end of the article
}

conditions. Not only may such changes be a useful indicator of stress (Marsh and Adams 1995; Cramer et al. 2002; Amarante et al. 2006; Renault et al. 2010) but they can reflect dynamic aspects of amino acid metabolism occurring in the root, often not apparent from analyses of amino acids of the source organ (Amarante and Sodek 2006).

Since the recognition of brassinosteroids as growth regulators, many studies have been carried out concerning their capacity of attenuating the effects of diverse types of stress, including salt stress (Zullo and Adam 2002; Ozdemir et al. 2004; Kagale et al. 2007). Despite such reports and the well documented adverse effects of salt on $\mathrm{N}$ metabolism, information is scarce (Anuradha and Rao 2001) regarding the influence of these hormones on nitrate uptake and metabolism under saline conditions.

Cajanus cajan (L.) Millsp. is a legume cultivated in the tropics and sub-tropics (Summerfield and Roberts, 1985 apud Akintayo et al. 1999). Their seeds are consumed 
as a supplement in flour or in natura (Corzo and Fuentes 2004). In a previous study (Dalio et al. 2011) 24-epibrassinolid reduced the inhibitory effects of $\mathrm{NaCl}$ on photosynthesis and several growth parameters of C. cajan plants. In this study, we investigated whether 24-epibrassinolide can revert the adverse effects of salt on growth of C. cajan through changes in nitrate uptake and metabolism. The effect of clotrimazole, an inhibitor of brassinosteroid synthesis (Amzallag and Vaisman 2006), was also studied. Although our study focused on $\mathrm{N}$ metabolism in the root (in contrast to many studies) we included the analysis of amino acids in the xylem sap in view of the absence of information regarding the influence of brassinosteroids on nitrogen transport to the shoot.

\section{Methods}

The study was carried out in Campinas, São Paulo State, Brazil $\left(22^{\circ} 49^{\prime} \mathrm{S}, 47^{\circ} 06^{\prime} \mathrm{W}\right.$, and $670 \mathrm{~m}$ of altitude). Seeds of Cajanus cajan (L.) Millsp, cultivar C11, supplied by the Agronomy Institute at Campinas, were allowed to imbibe in distilled water for 48 hours and then sown in $700 \mathrm{~mL}$ plastic pots, containing perlite. The plants were grown in the greenhouse for approximately 50 days, under natural light and temperature $\left(19\right.$ to $\left.40^{\circ} \mathrm{C}\right)$ conditions, from February to April of 2007. The pots were watered daily with tap water until the fall of the cotyledons. At this stage each pot, containing a single plant, received $150 \mathrm{~mL}$ of Hoagland and Arnon's (1938) normal-strength nutrient solution, with or without added $\mathrm{NaCl}$.

During the exposure of plants to saline stress, the plants were given gradually increasing concentrations of salt, in order to avoid osmotic shock. The saline concentrations were increased by $50 \mathrm{mM}$ every two days, until the final concentration of $400 \mathrm{mM}$ were reached. In all, the plants were exposed to salt for 16 days.

In order to guarantee uniform exposure of the roots to the salt, the pots (with holes in the base) were placed inside a second pot of greater diameter with no holes containing excess nutrient solution (to a depth of about $1 \mathrm{~cm}$ ). This ensured that the nutrient solution kept the perlite moist up to the surface by capillary action. Before each application of nutrient solution, the outer pot was removed and the inner pots washed with $150 \mathrm{~mL}$ of nutrient solution, in order to avoid salt accumulation. The pots were allowed to drain for several hours, so as to avoid dilution of the subsequently added salt/nutrient solution.

The brassinosteroid 24-epibrassinolide (Sigma-E1641) was applied to the substrate one week before the application of salt. The hormone was dissolved in ethanol (1 $\mathrm{mg} \mathrm{mL}^{-1}$ ) and diluted in nutrient solution to final concentrations of $10^{-7} \mathrm{M}$ and $0.5 \times 10^{-9} \mathrm{M}$.

The inhibitor of steroid synthesis Clotrimazole (Sigma C6019) was first dissolved in DMSO (dimethylsulfoxide) and then added to the nutrient solution (in the proportion of $1 \mathrm{~mL}$ of DMSO L ${ }^{-1}$ of solution) to give a concentration of $10^{-4} \mathrm{M}$ and applied to the substrate one week before the application of the salt.

The roots were harvested under running water: one part was used for measuring nitrate reductase activity and the rest for extraction of metabolites. The latter portion of roots was frozen, lyophilized and ground in a mortar. The powder was extracted with methanol: chloroform: water (MCW - 12:5:3 v/v) (Bieleski and Turner 1966). The extract was kept at $5^{\circ} \mathrm{C}$ for 24 hours and then centrifuged at $2000 \mathrm{~g}$ (Fanem, 215, Brazil), for 30 minutes. The supernatant was collected and, for each $4 \mathrm{~mL}, 1 \mathrm{~mL}$ of chloroform and $1.5 \mathrm{~mL}$ of water were added followed by vigorous shaking. After standing for 24 hours, the chloroform phase was discarded and the aqueous phase left in a water bath at $38^{\circ} \mathrm{C}$, for 8 hours, to eliminate residual chloroform and concentrate the samples. Then, the samples were centrifuged at $14000 \mathrm{~g}$ (Beckmann, Avanti J30 I, USA) for 5 minutes, and the supernatant collected. Samples were stored at $-20^{\circ} \mathrm{C}$ (Operon Co. Ltd, Korea) and used for the determination of nitrate and free amino acids. The residue after MCW extraction was retained for the determination of root protein content.

To evaluate the concentration of proteins the residue after MCW extraction was suspended in $10 \mathrm{~mL}$ of $0.1 \mathrm{~N}$ $\mathrm{NaOH}$ and homogenized with a glass rod. After 24 hours of extraction the suspension was centrifuged at $2000 \mathrm{~g}$ for 30 minutes. The supernatant was used for the determination of protein as described by Bradford (1976), using bovine serum albumin as standard.

Nitrate determination followed the method of Cataldo et al. (1975) using $\mathrm{KNO}_{3}$ as standard and free amino acids were determined according to Yemm and Cocking (1955), using leucine as standard.

Nitrate reductase was extracted and assayed essentially as described by Botrel and Kaiser (1997). Nitrite in the assay was determined on aliquots removed at zero time and after 30 minutes incubation according to Hageman and Reed (1980).

The xylem bleeding sap was collected according to Mc Clure and Israel (1979). The stem was severed with a razor blade just below the cotyledonary node and the exudate collected with microcapillaries. Sap samples were stored frozen until further analysis.

Amino acid composition of xylem sap was determined by reverse phase HPLC (LKB 2150, Spectra Physics Ltd, USA) of the o-phthaldialdehyde (OPA) derivatives based on the method of Jarret et al. (1986), with modifications (Thomas et al. 2005).

The trials were set up in a completely randomized design. One concentration of $\mathrm{NaCl}$ was used at $400 \mathrm{mM}$ together with a control ( $\mathrm{NaCl}$ absent). Plants were cultivated with and without previous application of 24- 
epibrassinolide (two concentrations) or clotrimazole, all in the presence and absence of salt, giving a total of 8 treatments. The treatments had 12 replicates, where each replicate consisted of a single pot with one plant. For the analysis of amino acid composition four replicates were used each consisting of material from three plants. The data were submitted to an analysis of variance (ANOVA) for three factors (salt, concentration of hormone and of clotrimazole). When significant interaction occurred the analysis of variance was repeated considering each treatment separately (One-Way ANOVA) and the means compared by Duncan's multiple range test $(\mathrm{p} \leq 0.05)$.

\section{Results}

Significant interaction was found between the three factors under study (salt, hormone and clotrizamole), for the various parameters evaluated. Each combination of variables was therefore analyzed separately.

The effect of salt on the levels of nitrate and nitrate reductase activity in roots of $C$. cajan plants are shown in Figure 1 and on the levels of free amino acids and soluble proteins in Figure 2. With the exception of soluble proteins, there were reductions in all parameters analysed.

In the absence of saline stress, applications of 24epibrassinolide led to small but significant increases in nitrate reductase activity as well as of nitrate (except at $\left.10^{-7} \mathrm{M}\right)$ and amino acids whereas clotrimazole resulted in reduced levels of nitrate and nitrate reductase activity (Figures 1 and 2).

If only plants cultivated under salinity are compared, it may be seen that applications of 24-epibrassinolide resulted in increases in all parameters of nitrogen metabolism measured while the inhibitor of these hormones lead to a reduction in nitrate and nitrate reductase activity, but not free amino acids or soluble proteins (Figures 1 and 2).

The effects of salinity and the 24-epibrassinolide on amino acid transport in the xylem sap of C. cajan plants may be seen in Figure 3, where data are shown for the more important amino acids (GLN, GLU, ASN, ASP, ALA), that is, those most closely associated with primary nitrogen assimilation and often prominent in nitrogen transport. SER was also included since it often follows changes in ALA associated with some stress conditions (Sousa and Sodek 2003). The amino acids transported in greatest amounts were ASN (40\% in the control) followed by GLU and ASP (17\% and 13\% respectively).

In general, under salt treatment or after the application of clotrimazole, it may be seen that the proportion of the three prominent amino acids (ASN, ASP, GLU) declined relative to the control. On the other hand, ALA and SER increased in most of the saline treatments, with and without hormone application. The only exception was ALA in plants cultivated under salinity and without hormone which did not differ from the control plants.

With the application of $10^{-7} \mathrm{M}$ 24-epibrassinolide in the absence of salt, the proportion of ASN increased to $65 \%$ of the amino acids transported in the xylem sap and in the treatment with the lower concentration of hormone (24epibrassinolide at $\left.0.5 \times 10^{-9} \mathrm{M}\right)$ the proportion of this amino acid reached approximately $50 \%$. This increase was accompanied by a decline in GLU and ASP. Clotrizamole, in the absence of salt, caused the opposite effect, a decline in ASN.

Under salt treatment it may be seen that the proportion of the three prominent amino acids (ASN, ASP, GLU) declined relative to the control, while ALA did not decline and SER increased under salt treatment. Application of

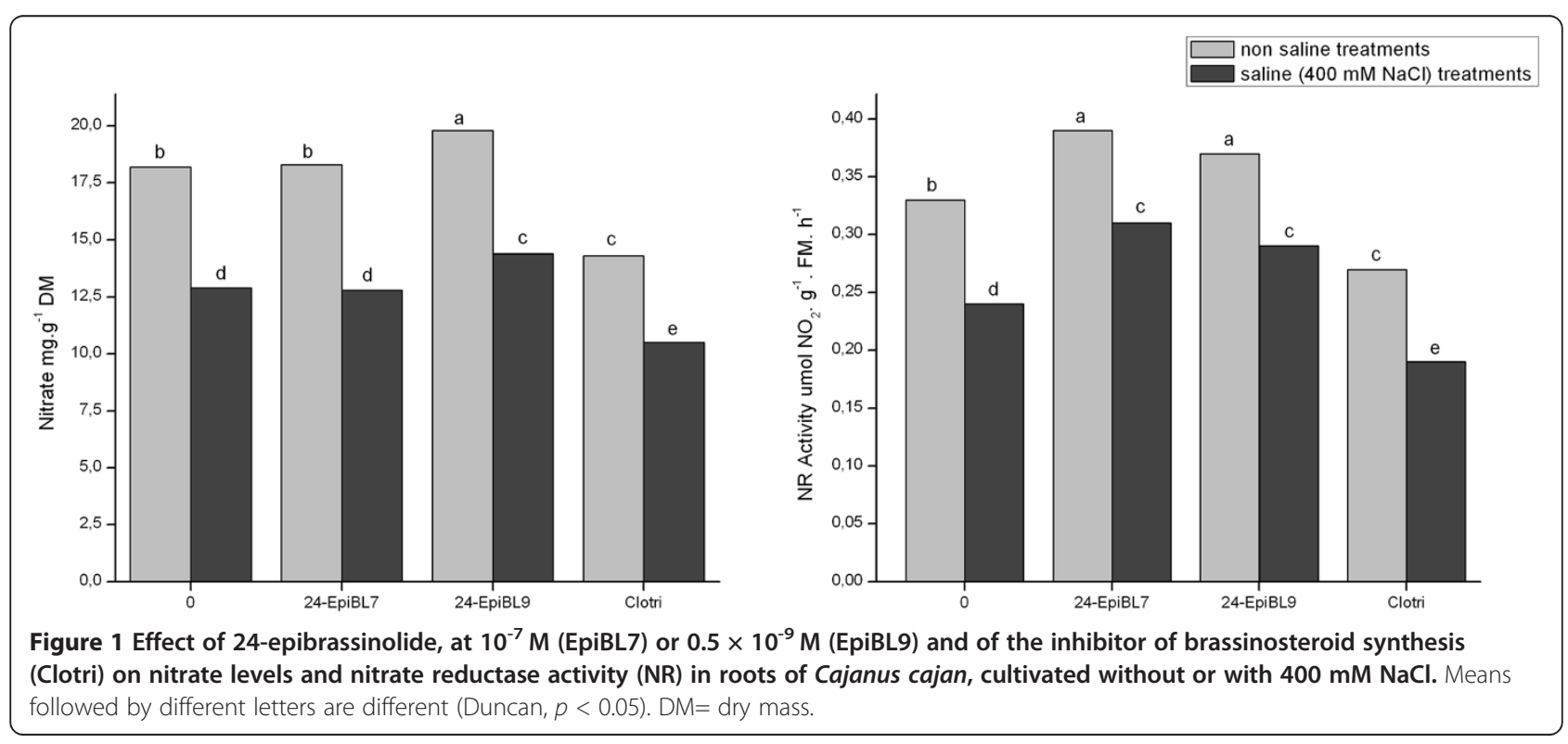




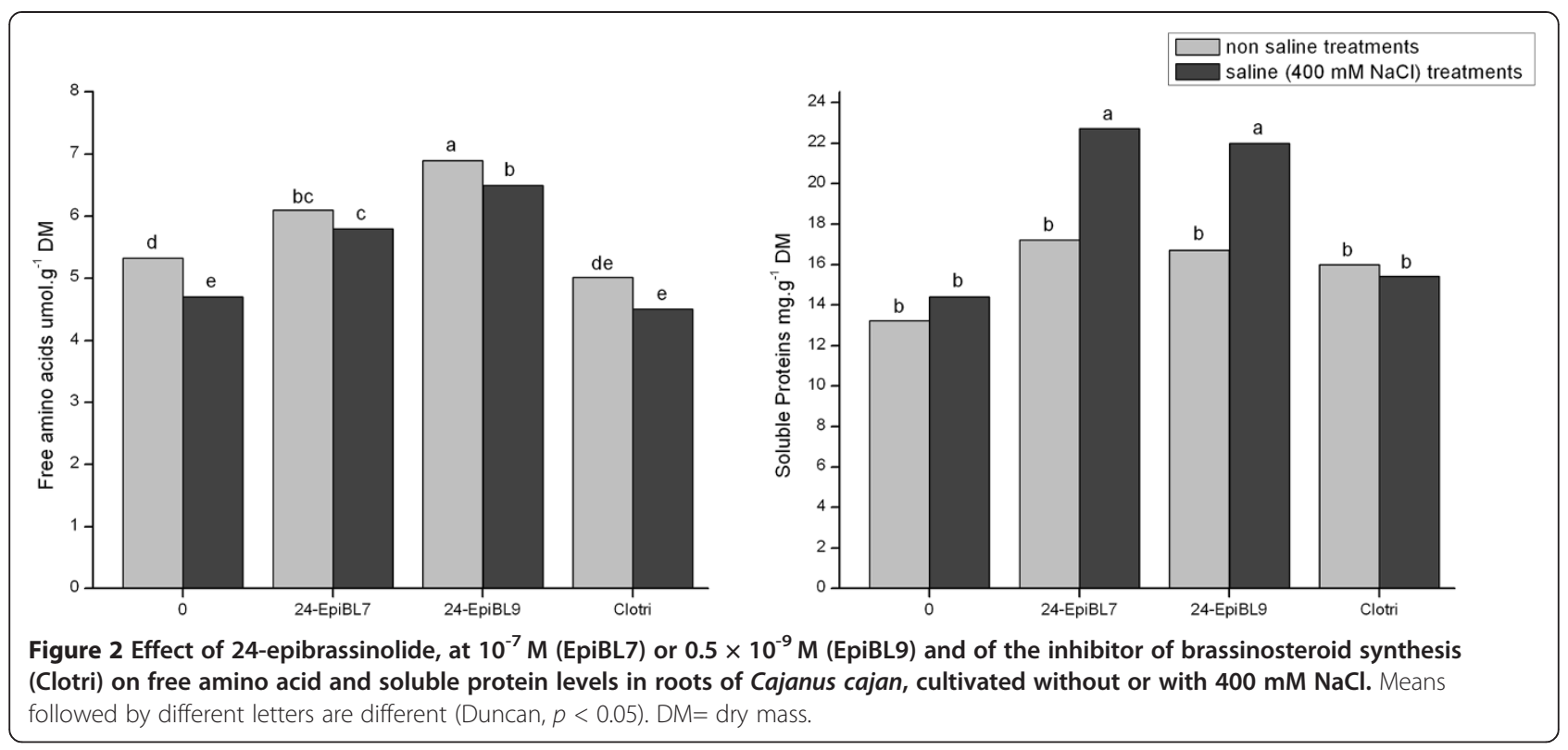

24-epibrassinolide to plants subjected to salt stress resulted in increases in proportions of the following amino acids in relation to the saline control: ALA, SER, GLN and GLU, and, at the lower hormone concentration at least, ASN. ASP, however, remained at a level similar to the salt control. These increases were not seen with the application of clotrimazole, while ASP showed an increase in contrast to the hormone treatment where it remained at the level of the salt control.

\section{Discussion}

The reduced level of root nitrate under saline conditions observed in this study is consistent with that observed for seedlings or leaves of other species (Silveira et al. 2003; Debouba et al. 2007), when cultivated under saline conditions. It is to be expected that reduced uptake of nitrate would lead to lower activity of nitrate reductase, as has been observed for other species (Hamdia et al. 2004; Iqbal et al. 2006; Debouba et al. 2007; Hasaneen et al. 2008), although only the first study included data for roots as in our study. Probably, the close relationship between nitrate assimilation and amino acid biosynthesis explains the reduced levels of free amino acids found in roots of C. cajan plants after salt treatment. In contrast to amino acids, the levels of soluble proteins were not affected by salinity. Stability of protein levels in C. cajan plants under saline stress was also observed by Ashraf (1994). Possibly, the maintenance of soluble protein levels reflects an increase in stress-specific proteins (Younis et al. 2009) that compensate a decline in other proteins.

The positive effect of 24-epibrassinolide with some parameters did not occur exclusively in the presence of salt, indicating that the hormonal effect was not necessarily salt specific. However, the effect of the hormone evidently has greater importance in the presence of salt stress. The positive effect of 24-epibrassinolide on nitrate levels for the C. cajan plants cultivated under salinity indicate increased uptake, leading to higher nitrate reductase activity, which in turn could explain the higher levels of free amino acids and soluble proteins. An increase in nitrate reductase activity was also reported by Anuradha and Rao (2001) following application of 24epibrassinolide in rice plants subjected to saline conditions. Possibly, brassinosteroids maintain the integrity of the cell membrane under stress conditions and consequently preserve the process of nitrate uptake. Hayat et al. (2007) found that 28-homobrassinolide reduced the inhibitory effect of cadmium on nitrate uptake of Brassica juncea and attributed the inhibitor effect of the metal to possible damage to the cell membranes.

Studies of amino acid export in the xylem under saline conditions are scarce in the literature (Cramer et al. 2002). Analysing changes in the amino acid composition of the xylem sap can be a powerful tool, since they can reflect changes in metabolic processes occurring in the source organs (Amarante and Sodek 2006). In this study ASN was the most abundant amino acid in the xylem sap, a general characteristic of legumes (Lea et al. 2007). Our data show diminished ASN in the xylem sap under saline stress, together with ASP, GLU and GLN. A reduction in the proportion of ASN in the root bleeding sap of Casuarina glauca under saline stress has also been reported (Cramer et al. 2002). Reduced xylem sap ASN can be attributed to diminished activity of asparagine synthetase in the root system (Lima and Sodek 2003; Antunes et al. 2008).

The reduction in the proportion of the amino acids ASN and GLN due to salinity was totally and GLU partially reverted by the application of 24-epibrassinolide, 


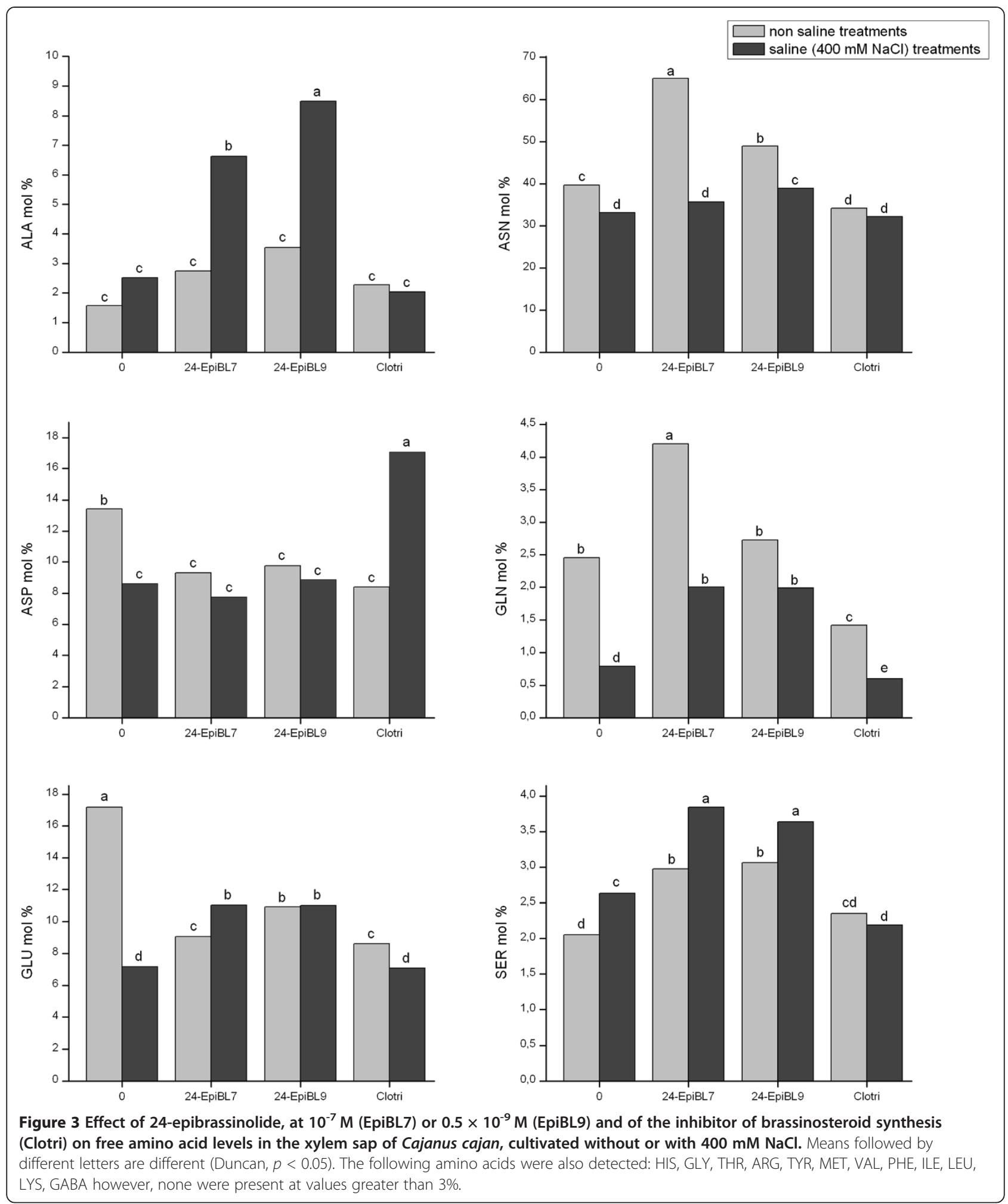

since the composition returned to values equal or closer to those seen for the controls without salt. Applications of the inhibitor of brassinosteroid synthesis resulted in reductions in the proportions of these amino acids in relation to the control in both the presence and absence of salt, reinforcing the idea that 24-epibrassinolide is associated with the increase in these amino acids in the xylem. We are unaware of any report concerning a 
possible mechanism of action of brassinosteroids in relation to the synthesis and transport of amino acids. However, it does seem that the hormone is involved in such processes, since the application of 24-epibrassinolide reestablished, at least partially, the proportions of these amino acids.

The strong positive effect of 24-epibrassinolide on ALA in the presence of salt (and to a lesser extent on SER) was not expected in view of the association of increased ALA (and SER) with abiotic stress (Puiatti and Sodek 1999; Sousa and Sodek 2002; Yazici et al. 2007). The hormone in the absence of salt and salt alone did promote small increases in these two amino acids, but the increases in ALA were not significant, suggesting a very weak association with salt stress. Perhaps in this case the increases in ALA and SER promoted by the hormone in the presence of salt were not related to a stress response. Rather, it would appear that salt does not interfere with the positive effect of the hormone on these two amino acids.

\section{Conclusion}

In conclusion, the positive effect of 24-epibrassinolide on nitrate uptake under salinity was reflected in the increased activity of nitrate reductase in the root, that probably underlies the higher levels of free amino acids and soluble proteins found in these organs. Application of the hormone also fully or partially restored the proportions of amino acids ASN, GLN and GLU, the products of primary nitrate diminished in the xylem sap by salinity. Application of the brassinosteroid synthesis inhibitor caused a decrease in the proportions of these amino acids and intensified the adverse effects of salinity on nitrate concentration and activity of nitrate reductase. Overall, the hormone exerts a beneficial effect on nitrogen metabolism in roots of C. cajan plants under saline stress and its mode of action would appear, therefore, to involve the restoration of $\mathrm{N}$ metabolism close to that found in unstressed plants.

\section{Abbreviations}

ASN: Asparagine; ASP: Aspartic acid; GLN: Glutamine; GLU: Glutamic acid.

\section{Competing interests}

The authors declare that they have no competing interests.

\section{Authors' contributions}

RJDD carried out the experiments. HPP was responsible for the statistical analyses. LS was responsible for the amino acid analyses. $\mathrm{CRBH}$ planned the experiments. All authors participated in writing the manuscript. All authors read and approved the final manuscript.

\section{Acknowledgements}

We wish to thank the Fundação de Amparo à Pesquisa do Estado de São Paulo for financial support of the project. Ronaldo J. D. Dalio acknowledges the Conselho Nacional de Desenvolvimento Científico e Tecnológico for the grant received and we thank Dr. Elaine B. Wutke for seeds of C. cajan.

\section{Author details}

${ }^{1}$ Department of Plant Biology, Institute of Biology, State University of Campinas-UNICAMP, CP 6109, Campinas, SP 13083-970, Brazil. ² Current address: Department of Ecophysiology of Plants, Technical University of Munich, Hanz-Carl-von-Carlowitz-Platz 2, 85354, Freising, Germany. ${ }^{3}$ Departament of Statistics, Institute of Mathematics, Statistics and Scientific Computation, University of Campinas-UNICAMP, Campinas, SP 13083-970, Brazil.

Received: 2 January 2012 Accepted: 7 September 2012

Published: 21 August 2013

\section{References}

Akintayo ET, Oshodi AA, Esuoso KO (1999) Effects of $\mathrm{NaCl}$, ionic strength and pH on the foaming and gelation of pigeon pea (Cajanus cajan) protein concentrates. Food Chem 66:51-56

Amarante L, Sodek L (2006) Waterlogging effect on xylem sap glutamine of nodulated soybean. Biol Plant 50:405-410

Amarante L, Lima JD, Sodek L (2006) Growth and stress conditions cause similar changes in xylem amino acids for different legume species. Environ Exp Bot 58:123-129

Amzallag GN, Vaisman J (2006) Influence of brassinosteroids on initiation of the root gravitropic response in Pisum sativum seedlings. Biol Plant 50:283-286

Antunes F, Sodek L, Pineda M, Aguilar M (2008) Nitrogen stress and the expression of asparagine synthetase in roots and nodules of soybean (Glycine max). Physiol Plant 133:736-743

Anuradha S, Rao SSS (2001) Effect of brassinosteroids on salinity stress induced inhibition of seed germination and seedling growth of rice (Oryza sativa L.). Plant Growth Regul 33:151-153

Ashraf M (1994) Salt tolerance of pigeon pea (Cajanus-cajan (L.) Millsp) at 3 growth-stages. Ann Appl Biol 124:153-164

Bieleski LR, Turner NA (1966) Separation and estimation of amino acids in crude plant extracts by thin-layer electrophoresis and chromatography. Anal Biochem 17:278-293

Botrel A, Kaiser WM (1997) Nitrate reductase activation state in barley roots in relation to the energy and carbohydrate status. Planta 20:491-501

Bradford MM (1976) A rapid and sensitive method for the quantitation of microgram quantities of protein utilizing the principle of protein-dye binding. Analytical Biochem 72:248-254

Carillo P, Mastrolonardo G, Nacca F, Fuggi A (2005) Nitrate reductase in durum wheat seedlings as affected by nitrate nutrition and salinity. Funct Plant Biol 32:209-219

Cataldo DA, Haroon M, Schrader LE, Youngs VL (1975) Rapid colorimetric determination of nitrate in plant tissue by nitration of salicylic acid. Commun Soil Sci Plant Anal 6:71-80

Corzo O, Fuentes A (2004) Moisture sorption isotherms and modeling for pre-cooked flours of pigeon pea (Cajanus cajans L. millsp) and lima bean (Canavalia ensiformis). J Food Eng 65:443-448

Cramer VA, Schmidt S, Stewart GR, Thorburn PJ (2002) Can the nitrogenous composition of xylem sap be used to assess salinity stress in Casuarina glauca? Tree Physiol 22:1019-1026

Dalio RJD, Pinheiro HP, Sodek L, Haddad CRB (2011) The effect of 24epibrassinolide and clotrimazole on the adaptation of Cajanus Cajan (L.) Millsp. to salinity. Acta Physiol Plant 33:1887-1896

Debouba M, Maaroufi-Dghimi H, Suzuki A, Ghorbel MH, Gouia H (2007) Changes in growth and activity of enzymes involved in nitrate reduction and ammonium assimilation in tomato seedlings in response to $\mathrm{NaCl}$ stress. Ann Bot 99:1143-1151

FAO (2008) Global network on integrated soil management for sustainable use of salt affected soils., Available at: http://www.fao.org/ag/AGL/agll/spush/intro. htm. [Accessed Dec. 22 2008]

Galvan-Ampudia CS, Testerink C (2011) Salt stress signals shape the plant root. Curr Opin Plant Biol 14:296-302

Hageman RH, Reed AJ (1980) Nitrate reductase from higher plants. Methods Enzymol 69:270-280

Hamdia ABE, Shaddad MAK, Doaa MM (2004) Mechanisms of salt tolerance and interactive effects of Azospirillum brasilense inoculation on maize cultivars grown under salt stress conditions. Plant Growth Regul 44:165-174

Hasaneen MNA, Younis ME, El-Bialy DMA (2008) Plant growth, metabolism and adaptation in relation to stress conditions: Further studies supporting 
nullification of harmful effects of salinity in lettuce plants by urea treatment. Plant Soil Environ 54:123-131

Hayat S, Ali B, Hasan AS, Ahmad A (2007) Brassinosteroid enhanced the level of antioxidants under cadmium stress in Brassica juncea. Environ Exp Bot 60:33-41

Hoagland DR, Arnon DI (1938) The water-culture method for growing plants without soil. California Agric Exp Station, Circular 347

Iqbal N, Ashraf MY, Javed F, Martinez V, Ahmad K (2006) Nitrate reduction and nutrient accumulation in wheat grown in soil salinized with four different salts. J Plant Nutr 29:409-421

Jarret HW, Cooksy KD, Ellis B, Anderson JM (1986) The separation of 0-phthalaldehyde derivatives of amino acids by reverse-phase chromatography on octysilica columms. Anal Biochem 153:189-198

Kagale S, Divi UK, Krochko JE, Keller WA, Krishna P (2007) Brassinosteroid confers tolerance in Arabidopsis thaliana and Brassinca napus to a range of abiotic stresses. Planta 225:353-364

Lea PJ, Sodek L, Parry MAJ, Shewry PR, Halford NG (2007) Asparagine in plants. Ann Appl Biol 150:1-26

Lima JD, Sodek L (2003) N-stress alters aspartate and asparagine levels of xylem sap in soybean. Plant Sci 165:649-656

Maaroufi-Dguimi H, Debouba M, Gaufichon L, Clément G, Gouia H, Hajjaji A, Suzuki A (2011) An Arabidopsis mutant disrupted in ASN2 encoding asparagine synthetase 2 exhibits low salt stress tolerance. Plant Physiol Biochem 49:623-628

Marsh NR, Adams MA (1995) Decline of Eucalyptus tereticornis near Bairnsdale, Victoria: insect herbivory and nitrogen fractions in sap and foliage. Aust J Bot 43:39-50

Mc Clure PR, Israel DW (1979) Transport of nitrogen in the xylem of soybean plants. Plant Physiol 64:411-416

Ozdemir F, Bor M, Demiral T, Türkan I (2004) Effects of 24-epibrassinolide on seed germination, seedling growth, lipid peroxidation, proline content and antioxidative system of rice (Oryza sativa $\mathrm{L}$.) under salinity stress. Plant Growth Regul 42:203-211

Parida AK, Das AB (2004) Effects of $\mathrm{NaCl}$ stress on nitrogen and phosphorous metabolism in a true mangrove Bruquiera parviflora grown under hydroponic culture. J Plant Physiol 161:921-928

Puiatti M, Sodek L (1999) Waterlogging affects nitrogen transport in the xylem of soybean. Plant Physiol Biochem 37:767-773

Qu C, Liu C, Ze Y, Gong X, Hong M, Wang L, Hong F (2011) Inhibition of nitrogen and photosynthetic carbon assimilation of maize seedlings by exposure to a combination of salt stress and potassium-deficient stress. Biol Trace Elem Res. doi:10.1007/s12011-011-9037-6

Renault H, Roussel V, El Amrani A, Arzel M, Renault D, Bouchereau A, Deleu C (2010) The Arabidopsis pop2-1 mutant reveals the involvement of GABA transaminase in salt stress tolerance. BMC Plant Biol 10:20. doi:10.1186/14712229-10-20

Rubinigg M, Posthumus F, Ferschke M, Theo J, Elzenga M, Stulen I (2003) Effects of $\mathrm{NaCl}$ salinity on ${ }^{15} \mathrm{~N}$-nitrate fluxes and specific root length in the halophyte Plantago maritima L. Plant Soil 250:201-213

Silveira JAG, Melo ARB, Viégas RA, Oliveira JTA (2001) Salinity-induced effects on nitrogen assimilation related to growth in cowpea plants. Environ Exp Bot 46:171-179

Silveira JAG, Viegas RD, Rocha IMA, Moreira ACDM, Moreira RD, Oliveira JTA (2003) Proline accumulation and glutamine synthetase activity are increased by salt-induced proteolysis in cashew leaves. J Plant Physiol 160:115-123

Sousa CAF, Sodek L (2002) The metabolic response of plants to oxygen deficiency. Braz J Plant Physiol 14:83-94

Sousa CAF, Sodek L (2003) Alanine metabolism and alanine aminotransferase activity in soybean (Glycine max) during hypoxia of the root system and subsequent return to normoxia. Environ Exp Bot 50:1-8

Surabhi G-K, Reddy AM, Kumasi GJ, Sudhakar C (2008) Modulations in key enzymes of nitrogen metabolism in two high yielding genotypes of mulberry (Morus alba L.) with differential sensitivity to salt stress. Environ Exp Bot 64:171-179

Thomas AL, Guerreiro SMC, Sodek L (2005) Aerenchyma formation and recovery from hypoxia of the flooded root of system of nodulated soybean. Ann Bot 96:1191-1198

Türkan I, Demiral T (2009) Recent developments in understanding salinity tolerance. Environ Exp Bot 67:2-9

Yazici I, Türkan I, Sekmen AH, Demiral T (2007) Salinity tolerance of purslane (Portulaca oleraceae L.) is achieved by enhanced antioxidative system, lower level of lipid peroxidation and praline accumulation. Environ Exp Bot 61:49-57
Yemm EW, Cocking EC (1955) The determination of amino acids with ninhydrin. Analyst 80:209-213

Younis ME, Hasaneen MN, Kazamel AMS (2009) Plant growth, metabolism and adaptation to stress conditions. XXVII. Can ascorbic acid modify the adverse effects of $\mathrm{NaCl}$ and manitol on amino acids, nucleic acids and protein patterns in Vicia faba seedlings? Protoplasma 235:37-47

Zheng Y, Wang Z, Sun X, Jia A, Jiang G, Li Z (2008) Higher salinity tolerance cultivars of winter wheat relieved senescence at reproductive stage. Environ Exp Bot 62:129-138

Zullo MAT, Adam G (2002) Brassinosteroid phytohormones-structure, bioactivity and applications. Braz J Plant Physiol 14:143-181

doi:10.1186/1999-3110-54-9

Cite this article as: Dalio et al: 24-epibrassinolide restores nitrogen

metabolism of pigeon pea under saline stress. Botanical Studies 2013 54:9.

\section{Submit your manuscript to a SpringerOpen ${ }^{\circ}$ journal and benefit from:}

- Convenient online submission

- Rigorous peer review

- Immediate publication on acceptance

- Open access: articles freely available online

- High visibility within the field

- Retaining the copyright to your article

Submit your next manuscript at $\gg$ springeropen.com 